ALPHA N 29 Diciembre 2009 (105-122)

ISSN 0716-4254

http://alpha.ulagos.cl

\title{
SUJETOS SOCIALES ANDINOS, ANTROPOLOGÍA Y ANTROPÓLOGOS EN CHILE ${ }^{1}$
}

Andean social subjects, anthropology and anthropologists in Chile

\section{Hans Gundermann K.* Héctor González C.**}

Resumen

Este trabajo analiza la relación entre antropología y grupos sociales indígenas andinos en el norte de Chile. Describe la trayectoria de la disciplina en el área y las varias representaciones de sujeto que ha construido durante el último siglo.

Palabras clave: Sujetos andinos, antropología regional, conocimiento antropológico.

Abstract

This article analyses the relationship between Anthropology and Andean Native social groups in North Chile. It describes the trajectory of the discipline in the region and the many representations of subject it has constructed over the last century.

Key words: Andean subjects, regional anthropology, anthropological knowledge.

\section{INTRODUCCIÓN}

El conocimiento que disponemos sobre los sujetos sociales indígenas (que clasificamos, genéricamente, como "pueblos andinos" o "sociedades andinas") guarda relación con el contexto histórico en que se elabora, lo que le provee criterios de pertinencia social y nexos ideológicos y políticos. También, este conocimiento es relativo al desarrollo de la antropología y disciplinas afines en cuanto a las orientaciones teóricas y metodológicas que presiden la construcción de ese conocimiento. Puesto que lo uno y lo otro han cambiado más de una vez, no es posible apreciar ese saber en los términos de una acumulación donde cada nueva adquisición se agrega a una obra que se completa progresivamente. Lo que sabemos hoy se informa, sin duda, de lo precedente y surge del esfuerzo por denotar una realidad, pero está siempre mediado por el sello que le imprimen los sujetos que formulan ese conocimiento, los límites que imponen las culturas disciplinarias e institucio-

1 Proyecto Fondecyt $N^{\circ}$ 1060973: “Comunidades translocales: grupos y redes sociales indígenas en un contexto de postcomunalidad”. 


\section{Hans Gundermann K. - Héctor González C.}

nales, los objetivos de conocimiento establecidos y los procedimientos preferentes; en suma, por sus escuelas y tradiciones (Alexander, 1990). Y estas no se suceden necesariamente las unas a las otras sino que, provistas a veces de una tenacidad centenaria, coexisten por largo tiempo. Pero ese saber es, también, performativo pues contribuye a constituir aquello que designa y describe (Bourdieu, 1999;2001). La actual categorización de los grupos sociales de los que aquí nos ocupamos, como "aymaras" o "atacameños”, es un buen ejemplo de esto. Por tanto, el conocimiento antropológico no sólo se especifica respecto de realidades cambiantes, la pluralidad de sus fuentes o la asincronía de sus expresiones, sino que también, de manera más compleja, por su propia eficacia social.

Analizaremos y discutiremos, a continuación, la trayectoria de la antropología regional, las características que adquiere el conocimiento por ella elaborado y las representaciones que construye acerca de grupos con inscripciones sociales de sujeto cambiantes. Primero, se pasa revista a la antropología y a los antropólogos del norte de Chile, sus momentos y orientaciones. Con apoyo en lo anterior se procede, luego, a definir los sujetos construidos por la disciplina y su relación con los sujetos sociales que son objeto de su acción intelectual. En el epílogo, se perfilan criterios para una práctica antropológica revisada que mira al siglo XXI.

\section{ANTROPOLOGÍA Y ANTROPÓLOGOS EN EL NORTE DE CHILE}

Desde la década de 1860 hasta el inicio de la profesionalización de la antropología — década de 1950 - los indígenas del norte del país ${ }^{2}$ fueron incluidos en varios estudios. Sus autores generaron información relevante desde formaciones profesionales e intereses de conocimiento heterogéneos. La delimitación de fronteras nacionales, el reconocimiento de territorios en conflicto y el catastro de recursos incentivaron varias exploraciones y estudios por parte de hombres de ciencia e ingenieros con conocimientos de geografía (Phillipi, 1860; Bertrand, 1879; 1885; San Román, 1896, y Risopatrón 1906;1910). ${ }^{3}$ También se hicieron presentes extranjeros, como Bowman (1924) que realizó una descripción geográfica de Tarapacá y Atacama, y Boman (1908) que concreta una de las primeras etnografías modernas con su descripción de la localidad de Susques. ${ }^{4}$ Durante el mismo periodo otros profesionales se interesaron por el origen, distribución y costumbres de los grupos indígenas, con un cambio de énfasis desde lo geográfico a uno

\footnotetext{
${ }^{2}$ Para ser más exactos, de las regiones anexadas por Chile a finales del siglo XIX.

${ }^{3}$ Por razones de espacio, de aquí en lo sucesivo nos limitamos a las referencias indispensables.

${ }^{4}$ Localidad de la antigua Provincia de Atacama que por ese entonces ya pertenecía a Argentina.
} 
etnológico e histórico. Autores como Uhle (1918-1922), Guevara (1925-1929) Latcham (1910-1928-1938) y unos años antes Medina (1882) escribieron acerca de los indígenas en la medida que representan la prehistoria y son, también, integrantes significativos de la historia nacional. En prácticamente todos ellos, y siguiendo las tendencias de la época, se presentan ideas históricas nutridas por premisas difusionistas y evolucionistas.

Por influencia de las antropologías centrales, la norteamericana en particular, desde la década de 1950 tiene lugar en Chile un aumento de las etnografías profesionales —especialmente las mapuches- y, a la vez, la institucionalización de la disciplina. Pero el panorama de la investigación etnológica en el norte del país es todavía poco auspicioso. Se destaca el trabajo de Mostny (1954) y Munizaga (1963); Munizaga y Gunckel (1958) en el área atacameña y, ya a finales de la década de 1960 e inicios de la siguiente, el de Solc (1975) entre los aymaras. ${ }^{5}$ En paralelo, la expansión universitaria favorece la actividad de historiadores con intereses de investigación regionales (las provincias del norte, sus ciudades, instituciones y procesos modernos) en que lo indígena es una entidad histórica periférica pero ineludible de constatar (Bermúdez 1973, 1987; Wormald 1966, 1968; Cassasas 1974a y b). Es, también, el periodo en que las ciencias sociales acompañan los procesos de reforma social que vive el país, cambios que alcanzan a los pueblos andinos a través de planes y programas de desarrollo. La investigación social sirve al propósito de diagnosticar los problemas de base que la acción estatal busca resolver. Destaca la presencia de geógrafos y de sociólogos, más que de antropólogos; en particular, Aranda et al. (1964), Alvarado (1970) y Taberna (1971). Ya en el gobierno de Allende habrá quien se plantee el cómo las sociedades indígenas andinas pueden acompañar el tránsito al socialismo (Taberna 1973). Si en la visión antropológica e histórica los sujetos andinos eran vistos como supervivencia y estaban desapareciendo, desde esta perspectiva constituyen un problema para el desarrollo, precisamente por su atavismo. Su propia marginalidad convoca la necesidad de integrarlos en un proyecto de cambio. A pesar del voluntarismo y exceso ideológico, cabe destacar el sentido de inclusión social que implicó esta propuesta.

Una antropología profesional desarrollada por cientistas sociales formados en centros universitarios nacionales se lleva a efecto recién durante los años de gobierno autoritario. En un primer momento, la generación de conocimientos sobre los indígenas del norte de Chile se retrae al alero que le prestan las sedes universitarias regionales. Los trabajos más importantes, según nuestro modo de ver, son los que realizaron Martínez (1974-1975-

\footnotetext{
${ }^{5}$ Este autor checo inaugura los estudios etnológicos aymaras en el país.
} 
Hans Gundermann K. - Héctor González C.

1976), Cereceda (1977), Provoste (1977-1979-1980), Larraín (1974) y van Kessel (1980). Priman perspectivas tradicionalizantes en las que el cambio es visto, en general, como una amenaza externa. La visión antropológica encapsula al indígena en la tradición, rechazando a veces la validez de las opciones de cambio tomadas por las propias comunidades. Es, también, un momento de diálogo y de convergencia entre la antropología social, la etnohistoria e, incluso, la arqueología, a través de la propuesta integradora de John Murra (1975-1978) acerca de la historia indígena andina y su especificidad económica y social. Toma, así, forma una concepción unitaria de los sujetos indígenas históricos de los Andes (Ecuador, Perú, Bolivia, norte de Chile y Noroeste argentino) y sus aplicaciones se prolongan bastante más allá de sus orígenes hasta incluir a las sociedades campesinas modernas y contemporáneas, ${ }^{6}$ lo que representa una categoría genérica a partir de la cual, metodológicamente, constituir lo andino como objeto de investigación.

Junto con la investigación que se desarrolla desde algunas agencias públicas, a comienzos de la década de 1980 surge otro enfoque hacia lo indígena. Se acompaña de una nueva manera de abordar su desarrollo, mediante el concurso de organismos no gubernamentales (ONGs). A su formación y crecimiento concurren varios antropólogos. Estas organizaciones plantean su actividad desde una crítica a las políticas estatales y al autoritarismo, incluyéndolas dentro de procesos históricos de dominación. A estos efectos, generaron varios estudios de las transformaciones sociales de los pueblos andinos, entre ellas, las económicas, pero también aquellas referidas a la religiosidad, la educación, las lenguas originarias, la identidad nacional, la salud o la organización social. Se asistió, por ese entonces, a una nutrida actividad editorial. ${ }^{7}$ La investigación también adquiere un carácter de diagnóstico dirigida a elaborar alternativas a las políticas del gobierno militar, sintetizables bajo la noción de etnodesarrollo. Otro aspecto novedoso es la constatación de que el problema indígena en el norte del país no es sólo un asunto rural sino, también, uno industrial y urbano, lo que suscita algunos estudios (González, J. 1987 y 1988; González, S. 1987, 1989; Grebe 1986a).

No obstante, la antropología social desaparece de las universidades regionales, producto del control político y de la censura ejercida por los rectores delegados del gobierno autoritario. La que se mantiene se origina desde la Universidad de Chile (Grebe 1983-1986b; Castro y Bahamondes

\footnotetext{
${ }^{6}$ El mejor exponente de la aplicación de las categorías de análisis de John Murra a una realidad andina chilena es Tristan Platt (1975). Para una discusión de su influencia en la antropología social del norte de Chile. Cfr. Gundermann y González (2008b).

${ }^{7}$ Detallada en Arriaza (1991) y también en Gundermann y González (2008a). La producción intelectual del periodo es cuantiosa, nos limitamos a señalar la que, a nuestro juicio, representa a los principales autores.
} 
1987-1988; Castro, V. 1986-1987) o es realizada por tesistas chilenos y extranjeros (de estos últimos, Bernhardson, 1982; Folla, 1989 y Lemeiris, 1987, entre los más notorios). En el campo de la historia andina se reconocen dos líneas. La que da continuidad a un tipo de investigación historiográfica inaugurada en los años de 1960, donde los indígenas aparecen en el contexto más amplio de la historia regional. Y otra que impulsa el desarrollo de la etnohistoria regional. A diferencia de la primera, la orientación general de sus trabajos, influidos por John Murra, puede calificarse de sustantivista cultural e internalista, en la medida que el énfasis de la interpretación de los hechos indígenas coloniales se coloca en las prácticas internas y las lógicas que presiden la acción andina. Las relaciones externas no son desconocidas, pero ellas ocupan un segundo plano (Hidalgo, 1983-1984-1986-1987; Martínez, 1985-1986).

La antropología de post-dictadura está marcada por la redemocratización del país y por una mayor apertura académica y de las agencias públicas a las ciencias sociales. Durante estos años tiene lugar una mayor institucionalización de la antropología, que el nuevo ambiente político hace posible. Este proceso sigue tres carriles. Uno de ellos es la incorporación de antropólogos en las universidades regionales quienes, junto con otros profesionales de las ciencias sociales, se embarcan en la creación de nuevas carreras, formación de postgrados y la continuidad de sus investigaciones, ahora sin la premura del diagnóstico o la urgencia de la denuncia y con el respaldo de mayores recursos. Otra vía es la contratación de antropólogos en organismos públicos, desde donde realizan su aporte a la documentación, planificación e intervención estatal desarrollista. La actividad de los ONGs, en tercer lugar, tiene un periodo inicial de crecimiento, favorecidas por una nueva relación con el Estado, pero derivan luego hacia organismos técnicos que ejecutan proyectos licitados por agencias públicas y, con los cambios, pierden capacidad crítica y nivel de investigación. Principalmente, aquellos que dieron continuidad a su trabajo en las universidades regionales y nacionales sostienen la producción de nuevos conocimientos acerca de los pueblos andinos. ${ }^{8}$ Algunas innovaciones de interés pueden destacarse. Una, la apertura hacia nuevos temas en la investigación andina como las relaciones de género (Carrasco, 1998; Gavilán, 1993-2002) la redistribución urbana de las poblaciones indígenas regionales (González, H. 1996-1997a-1997b) los procesos étnicos de la década de 1990 y la presente (Gundermann, 1995-

\footnotetext{
${ }^{8}$ A lo que cabe agregar un numeroso contingente de alumnos que han realizado sus tesis de licenciatura y de magíster con algunos de los pueblos indígenas regionales. Frecuentemente, bajo la conducción y tutoría de investigadores con experiencia en la zona. Se consignan en detalle en Gundermann y González (2008a).
} 
Hans Gundermann K. - Héctor González C.

1997-2003a-2004a), o la historia andina moderna (Gundermann, 2003b-2007; González S., 2002). Otra, los cambios en la comprensión de los sujetos colectivos andinos y su cultura, que ahora se representan de manera más compleja y dinámica (Tudela, 2002; Gundermann, 2004b). Una tercera es el surgimiento, tímido todavía pero que promete aumentar, de intelectuales indígenas aymaras y atacameños que se pronuncian acerca de temas como la identidad cultural, la lengua, la educación intercultural o las prácticas tradicionales (Chipana, 1996; Mamani, M. 1999; Escalante, 2001 y Mamani J.C., 2003). ${ }^{9}$

\section{LOS SUJETOS DE LA ANTROPOLOGÍA}

El principal objeto de la práctica antropológica son los "pueblos andinos" o el "hombre andino". ${ }^{10}$ No se ha desarrollado una antropología regional de otros sujetos sino de aquellos así nombrados. Puesto que son relativos a las tomas de posición de los investigadores y, más allá, a las escuelas de pensamiento por las que son influidos, se puede esperar que haya tantos objetos como antropologías los hayan constituido a través de su acción intelectual. Entendiendo que estos posicionamientos no se desarrollan o aplican en un vacío social, a las entidades sociológicas propuestas por ese quehacer constructivo corresponden sujetos sociales más o menos definibles o difusos, según los casos. En esta medida, la relación entre sujeto y objeto antropológico es más compleja de lo que cabría suponer. Por otra parte, estos objetos no son específicos a la región sino, más bien, relativos a tradiciones intelectuales y escuelas antropológicas. En su labor constructiva se han tomado en préstamo conceptos, categorías y representaciones aplicadas o provenientes de otras partes, que se han adecuado para representar a los sujetos regionales.

Según se puede colegir, los sujetos antropológicos más importantes que se han construido son los siguientes. Primero, los pueblos relictuales. Esta adjetivación con antecedentes botánicos parece ser la más adecuada para caracterizar la forma de apreciar, diagnosticar y valorar las poblaciones indígenas regionales que entregan los etnólogos, arqueólogos y otros profesionales interesados en estos grupos, desde la mitad del siglo XIX hasta mediados del siglo XX. La imagen que prevalece es la de grupos

\footnotetext{
${ }^{9}$ Cabe recordar que en esta diversa construcción de conocimiento no sólo han participado etnógrafos, por lo que también prestamos atención a otras disciplinas y profesionales cuyos intereses convergen sobre esos objetos y contribuyen a su creación.

${ }^{10}$ La antropología y buena parte de la investigación social que históricamente se ha llevado a efecto en el norte de Chile están referidas a los pueblos indígenas aymara, atacameño, quechua y colla, andinos por su filiación histórico cultural.
} 
sobrevivientes del pasado, reducidos espacialmente a los márgenes geográficos de la región, disminuidos numéricamente, prontos a ser asimilados y, por tanto, condenados a desaparecer. Es una visión pesimista acerca del futuro indígena, por lo cual los conocimientos que se generan tienen el sabor del rescate cultural. Para explicar su presencia y estado, se aplican conceptos de origen difusionista (hipótesis históricas de génesis, distribución, intercambio y préstamos culturales) y evolucionista (grupos que han quedado fuera de un curso histórico central y ajenos al proceso de la civilización). Estas interpretaciones consideran enormes lapsos y cubren extensas regiones geográficas.

Los grupos interpelados tenían de sí mismos una visión bastante diferente de la propuesta por etnógrafos y por otros estudiosos que escribieron sobre ellos. Con importantes variaciones según los grupos y los sectores, éstos se ubicaban a sí mismos al interior de lo que hemos llamado el "paradigma semántico del progreso” (Gundermann, 2003a). ${ }^{11}$ Esta perspectiva aprecia grupos que por sus formas de vida y condición social se encuentran en el extremo más tradicional y atrasado de la sociedad y, en estos términos, es convergente con la representación de pueblos remanentes, pero se diferencia en que no enfatiza la continuidad cultural sino el cambio y la jerarquía de posiciones que los grupos ocupan en una escala de progreso. De esta manera, el objeto antropológico representado y las representaciones del sujeto soporte de esas imágenes guardaban entre sí una clara diferencia. No obstante, según se puede apreciar desde la actualidad, es una antropología que produce distinciones y definiciones que, paradojalmente, varias décadas más tarde serán la materia prima desde la cual establecer clasificaciones y tipificaciones étnicas.

Un segundo enfoque antropológico corre con éxito desde la década de 1950 en adelante y mantiene vigencia parcial hasta hoy: es el de la comunidad campesina indígena. Tiene su origen en la reorientación del objeto de la antropología que se lleva a efecto en muchos lugares del mundo, luego que las sociedades de Outre Mer fueran crecientemente integradas a los sistemas estatales nacionales y globales (Kearney, 1996). El campesinado, sus localidades y comunidades serán en lo sucesivo un objeto preferente de la disciplina, porlo menos, en las áreas nucleares de Latinoamérica (Mesoamérica

\footnotetext{
${ }^{11}$ Esta noción designa una forma de conciencia social moderna en que la representación colonial de los indígenas como un cuerpo o estamento diferenciado de la sociedad cede el paso — durante el siglo XIX — a otra organizada por un principio de jerarquía universal basado en la mayor o menor distancia que los grupos humanos mantienen respecto de un estado de "progreso". Ernest Gellner lo expresa bien: "Un solo camino que conduce a cosas mejores y por el cual se mueve toda la humanidad aunque a diferentes velocidades; ésa es la idea del progreso" (1993:58).
} 


\section{Hans Gundermann K. - Héctor González C.}

y los Andes). De esta manera, el conocimiento buscado por la antropología deberá encontrarse en las instituciones locales comunitarias y en la vida pueblerina.

Se ha discutido el carácter funcionalista, internalista y, por tanto, descontextualizado del conocimiento logrado por la investigación orientada de esta manera. Los grupos sociales —objeto de esta antropologíaaparecen, con más frecuencia de la deseada, asépticos o indemnes con relación al capital mercantil e industrial, a los mercados de fuerza de trabajo, a las formas de dominación tradicionales, a la acción desarrollista del Estado. La explicación de su realidad y dinámica, entonces, queda en buena medida librada a las instituciones y a las fuerzas sociales internas. El momento histórico que se vive en América Latina, y en Chile, corresponde al del desarrollo capitalista endógeno, con una creciente integración de territorios y de poblaciones nacionales. Es un momento, también, de luchas sociales (campesinas) y reformas (como las agrarias) de las cuales los indígenas andinos fueron partícipes. Nuevamente aquí, el objeto antropológico sostiene una relación contradictoria con el sujeto de conocimiento: mientras este se conforma sociológicamente en las relaciones externas (movimientos sociales, desarrollismo, reforma agraria) esa antropología los constituye como un objeto del que se privilegian sus dimensiones internas (las de los sujetos en su vida comunal o local).

La del hombre andino constituye una de las representaciones de sujeto más influyentes en los estudios antropológicos regionales de las décadas de 1970 y 1980. Incide, posiblemente, más en los arqueólogos y etnohistoriadores nacionales que en los antropólogos. El alcance de la propuesta es bastante amplio, subregional. Surge y se desarrolla desde los estudios etnohistóricos, etnológicos y, en menor medida, arqueológicos efectuados en los países andinos por parte de algunas misiones científicas norteamericanas. A ellas se pliegan, con prontitud, investigadores europeos y antropólogos locales. Uno de sus grandes atractivos radica en el esfuerzo por identificar continuidades en las lógicas sociales, instituciones, patrones culturales, prácticas y relaciones económicas de los pueblos indígenas andinos actuales con los del pasado, sea en términos de persistencia o de reelaboración.

Se trata de una perspectiva antropológica igualmente internalista que aquella que se ocupa del estudio de la comunidad campesino indígena. Pero, en este caso, el sujeto andino no se define por una recontextualización histórica (integración colonial, campesinización de las economías étnicas, etc.) sino por su pertenencia a un espacio civilizatorio: el andino. Contiene, en esta medida, el presupuesto —al menos para ciertas áreas y circunstanciasde un sujeto con capacidad para perdurar históricamente en el largo plazo. No desconoce los contextos socio-históricos, pero no los privilegia. Uno de los 
mayores problemas de esta construcción del objeto antropológico radica en la dificultad de incorporar plenamente las discontinuidades sociales e históricas y la trasformación, a veces de gran alcance, de los sujetos que surgen y cambian con los avatares históricos regionales. La polisemia de su cultura, la hibridez de sus prácticas, la novedad de muchas de sus relaciones sociales, la modernidad de algunas formas de organización, la heterogeneidad de su sociedad, las contradicciones que recorren su vida social, la complejidad de las ecuaciones entre tradición e innovación, todo ello tiende a diluirse o a quedar en un segundo plano.

Representaciones de este tipo han conducido a argumentaciones y a planteamientos realmente forzados. Es el caso de las tesis de la "desestructuración" andina regional, cuyo postulado supone un estado previo de "estructuración" y ese estado inicial se tiende a plantear en una larga duración, incluso prehispánica. La contextualidad socio-histórica y de los sujetos andinos se debilita a tal punto que la historia se hace inocua, aunque sólo hasta el momento cuando irrumpe la modernidad y empieza la “desestructuración” o el "holocausto al progreso". Se trata, entonces, de un enfoque crítico de la modernidad en los Andes, pero complaciente y conservador en cuanto a la prolongada y agitada historia anterior. Aunque indirectamente la antropología del hombre andino también influyó en que no se desarrollara una antropología de las relaciones con el Estado, como ocurre en el sur del país respecto del pueblo mapuche. Ésta sólo aparecerá a fines de la década de 1980, pero sin que se resuelva en la construcción de un nuevo sujeto; quizá por la debilidad de los movimientos sociales andinos y por el avance logrado por la representación de un nuevo objeto-sujeto antropológico: el de los pueblos originarios.

La etnia, el pueblo y, a veces, la nación son los conceptos presentes en la constitución del sujeto de conocimiento más reciente dentro de las preocupaciones de la antropología nortina. Este sujeto y la antropología que lo observa - y a veces lo acompaña- guardan entre sí una antigua complicidad: la que proviene de la adopción y naturalización, por unos (los intelectuales, líderes y dirigencias aymaras, atacameñas, quechuas y collas), de la representación que se había forjado respecto de su objeto la primera antropología (“culturas” en estado de supervivencia). Con ello no se quiere plantear una relación de paternidad de la antropología en la formulación de estos nuevos sujetos étnicos sino, simplemente, consignar un nexo anterior al momento reciente en que la antropología aborda estos nuevos sujetos indígenas. Como se sabe, esta nueva realidad de sujeto se conforma sólo en las últimas décadas, con la concurrencia de un conjunto de factores: emergencia de nuevos tipos de movimientos sociales en un escenario de intensificación de la globalización, expansión de una sensibilidad cultural por 
Hans Gundermann K. - Héctor González C.

la diferencia, generación de nociones jurídicas y políticas que promueven el reconocimiento de minorías lingüísticas y culturales y de grupos nacionales subordinados. En Chile, específicamente, concurren la acción de organismos no gubernamentales opositores al gobierno autoritario, la mayor sensibilidad sobre estos temas en una parte de la clase política en el escenario de postdictadura y la redefinición de los movimientos indígenas nacionales, en particular el mapuche.

Resulta indispensable destacar que, por primera vez, se estaría dando una concordancia entre un sujeto social - los pueblos o etnias andinas con conciencia, organización, voz y movimiento, en tanto que tales- y la definición de un objeto antropológico así representado. Y esto de dos maneras: por el modo como cierto número de antropólogos define el sentido del conocimiento: en la estela de una antropología de apoyo; y por la orientación de la investigación: preferentemente en temas de índole sociopolítica. De ello deriva una práctica antropológica marcada por la urgencia, donde el sello característico es la presencia con y la utilidad del conocimiento generado para los sujetos. Ciertamente, existen matices según los autores, pero esa parece ser la nota predominante en esta inédita convergencia entre sujetos sociales y objeto antropológico en esta nueva forma de antropología de cara al siglo XXI.

\section{EPÍLOGO}

El recuento de la producción de conocimiento enseña que la constitución de los sujetos sociales andinos es una realidad construida en una relación dinámica entre varios términos. Por un lado, la formación de la ciencia antropológica en el país (a la zaga de los procesos de conformación disciplinaria mundial). Por otro, la construcción de objetos intelectuales, en una vinculación real, pero no siempre directa ni clara, con los fenómenos de la modernidad y con los procesos de modernización. Por último, el mismo flujo de lo social andino y de sus sujetos, envueltos en esos procesos modernizadores y abordados en esa relación por una práctica antropológica sometida a parámetros disciplinarios.

Esta antropología no sólo es del norte, sino también "andina”. Lo ha sido por acción, ya que, aunque varíen los principios sobre los cuales se asienta la construcción de objetos (presentes en la tipología de sujetos antropológicos propuesta más arriba) todos remiten o tienen por referencia la macrorregión andina y su historia socio-cultural. Y ha sido andina, también, por omisión, puesto que sólo recientemente se han empezado a abrir otros campos de construcción de conocimiento (antropología médica, antropología de la educación, antropología de la minería, etc.) donde los pueblos indígenas 
son sólo uno entre otros de los sujetos colectivos posibles de considerar. ${ }^{12}$ Pero ¿Cómo abordar lo andino? ¿Cómo continuidad cultural objetiva o como una realidad de grupos portadores de proyectos de cambio orientados a reforzar diferencias culturales? Un acto de prudencia aconseja tratar lo andino como un recurso metodológico, como un concepto límite que ayuda a pensar e investigar. Se puede considerar como el postulado de una unidad mínima, a la vez histórica y antropológica, de poblaciones y grupos cuyo origen es prehispánico. Correspondería, por así decirlo, a la cara continuista del enfoque que se propone. Pero no necesariamente para encontrar su persistencia sino, incluso, para negarla o consignar su ausencia, su transformación o su fusión. Es un concepto referencial, una herramienta conceptual útil para la definición de un objeto posible.

Dicho esto, ¿Cuáles pueden ser los objetos antropológicos del siglo XXI? No es dable saberlo porque, como se ha insistido, resultan siempre de una relación entre escuelas antropológicas y sujetos sociales en un momento histórico dado. Sí se puede aseverar algo más general: que dada la pluralidad de las orientaciones disciplinarias y la diversidad de actores sociales andinos actuales, y en gestación, difícilmente podrá surgir una referencia antropológica unitaria. Se puede pronosticar que tendremos, más bien, objetos de conocimiento plurales y en situación de coexistencia. Cualquiera sea el caso, si la antropología regional quiere avanzar, debe tanto remitirse al postulado de esa unidad mínima como aceptar la transformación de su objeto (de los sujetos sociales andinos). Pero, también, debe ir un paso más allá para destacar que las propias condiciones de formación de los sujetos sociales han cambiado por relación al pasado. En ese abordar los desafíos que plantean estas nuevas bases de formación de lo social y la complejidad y pluralidad de los sujetos sociales andinos, la antropología debe crear o debe tomar prestadas las herramientas teóricas y metodológicas más apropiadas. Constituye, en ese sentido, una antropología crítica que cuestiona las figuras preestablecidas o ideologizadas de lo andino — que rompe con los estereotipos acerca de lo indígena - y que se dirige a abordar sujetos colectivos heterogéneos, dinámicos y complejos.

\footnotetext{
${ }^{12}$ Hay espacio para otras antropologías regionales como, por ejemplo, una de la realidad histórico-cultural y presente de la minería del norte del país. Véase en esta línea el trabajo de Rodríguez et al. (2002) el proyecto Fondecyt N 1060092 "María Elena, cambio y reestructuración cultural, una cartografía antropológica de sus marcadores” (2006) del mismo investigador, así como el que inicia Jorge Pavés (Fondecyt $N^{\circ}$ 11080269) "Trabajo minero y trabajo sexual: configuraciones materiales y discursivas de las relaciones de sexo / género en las ciudades mineras del Norte Grande” (2008).
} 
Hans Gundermann K. - Héctor González C.

Universidad Católica del Norte*
Instituto de Investigaciones Arqueológicas y Museo (IIAM)
Gustavo Le Paige 380, San Pedro de Atacama (Chile)
hgunder@ucn.cl

Universidad de Tarapacá**

Departamento de Antropología, Facultad de Ciencias Sociales y Jurídicas

18 de Septiembre 2222, casilla 6-D, Arica (Chile)

hgonzale@uta.cl

\section{BIBLIOGRAFÍA}

ALEXANDER, Jeffrey. "La centralidad de los clásicos", en La teoría social hoy. Anthony Giddens y Jonathan Turner (Eds.). México D.F: Conaculta-Alianza (1990):22-80.

ALVARADO, Luis. La Vida Rural en el Altiplano Chileno. Santiago: ICIRA, 1970.

ARRIAZA, Patricio. Fuentes Bibliográficas para el Estudio de los Aymaras del Norte de Chile. Iquique: El Jote Errante, 1991.

ARANDA, Ximena; BARAHONA, Rafael; SAÁ, René. Elementos Diagnósticos para un Plan de Desarrollo Local en San Pedro de Atacama. Santiago: CORFO-Instituto de Geografía de la Universidad de Chile, 1964.

BERMÚDEZ, Oscar. El Oasis de Pica y sus Nexos Regionales. Arica: Universidad de Tarapacá, 1987.

------- "Pica en el siglo XVIII, estructura económica y social”, en Revista Chilena de Historia y Geografía No 141 (1973):7-56.

BERNHARDSON, Wayne. Natural Resources in an Andean Pastoral Economy: the Aymara of Parinacota, Chile. Berkeley: University of California, Department of Geography, Master of Art Dissertation in Geography, 1982.

BERTRAND, Alejandro. Noticias del Departamento Litoral de Tarapacá i sus Recursos. Santiago: Imprenta Nacional, 1879.

------- Memoria sobre las Cordilleras del Desierto de Atacama i Rejiones Limítrofes Presentada al Señor Ministro del Interior. Santiago: Imprenta Nacional, 1885.

BOMAN, Eric. Antiquités de la Région Andine de la République Argentine et du Désert d'Atacama. París: Impremerie Nationale, 2 vols., 1908.

BOURDIEU, Pierre. Langage et Pouvoir Symbolique. Paris: Fayard, 2001. 
Sujetos sociales andinos, antropología y antropólogos en Chile

¿Qué Significa Hablar? Madrid: Akal, 1999.

BOWMAN, Isaiah. Desert trails of Atacama. Nueva York: American Geographical Society, Special Publications No 5, 1924.

CARRASCO, Ana María. "Constitución de género y ciclo vital entre los aymaras contemporáneos del Norte de Chile”, en Chungara $\mathrm{N}^{\circ} 30$ (1998):87-103.

CASSASAS, José María. Fuentes Documentales para el Estudio Etnohistórico de las Poblaciones Indígenas del Norte Grande Chileno y Tierras Adyacentes. Antofagasta: Universidad del Norte, 1974a.

------- La Región Atacameña en el Siglo XVII: Datos Históricos Socioeconómicos sobre una Comarca de América Meridional. Antofagasta: Universidad del Norte, 1974b.

CASTRO, Milka; BAHAMONDES, Miguel. "Control de la tierra en la cabecera del valle de Lluta”, en Revista Chilena de Antropología $\mathrm{N}^{\circ} 7$ (1988):99-113.

------- "Cambios en la tenencia de la tierra en un pueblo de la precordillera del Norte de Chile: Socoroma”, en Revista Chilena de Antropología $\mathrm{N}^{\circ} 6$ (1987):35-57.

CASTRO, Victoria. Diagnóstico agrícola Provincia de El Loa: Estudios antropológicos. Santiago: Consultores Ecológicos y Ambientales, Informes I, II y III, 1987.

------- "An approach to the Andean Etnozoology: Toconce”, en Cultural attitudes to animals including birds, fish, and invertebrates. Londres: The World Archaeological Congress, 1-7 September 1986, Allen \& Unwin, Vol. 2, Sección B (1986):1-18.

CERECEDA, Verónica. Las talegas de Isluga: Apuntes para una semiología del textil andino. Iquique: Universidad de Chile, Centro Isluga, 1977.

CHIPANA, Cornelio. "La universidad y los pueblos indígenas: mito y realidad”, en Universidad y Pueblos Indígenas. Morales, Roberto (comp.). Temuco: Universidad de la Frontera, Instituto de Estudios Indígenas (1996):79-86.

ESCALANTE, Manuel. "La mesa de Todos Santos en San Pedro de Atacama, Chile”, en Chungara Nº 33 (2001):245-248.

FOLLA, Juan Carlos. Anthropologie Économique d'une Communauté Paysanne du Désert d'Atacama: Socaire. Montreal: Université de Montreal, Faculté des Études Supérieures. Tesis para optar al grado de Magíster en Ciencias Antropológicas, 1989.

GAVILÁN, Vivian. "Buscando vida: Hacia una teoría aymara de la división del trabajo por género”, en Chungara № 34 (2002):101-117.

"Relaciones de género en la cultura aymara: Complementariedad y subordinación”, en Montecino, Sonia y María Elena, Boisier (Eds.). 
Hans Gundermann K. - Héctor González C.

Huellas, Seminario Mujer y Antropología. Santiago: CEDEM (1993): 83-95.

GELLNER, Ernest. "Zenón de Cracovia o Revolución en Nemi o El desquite polaco. Drama en tres actos”, en Cultura, identidad y política. Gellner, Ernest. El nacionalismo y los nuevos cambios sociales. Barcelona: Gedisa (1993):58-85.

GONZÁLEZ, Héctor. "La inserción económica de los migrantes aymara en la ciudad: el trabajo como empresa familiar y la reproducción cultural”, en Actas Segundo Congreso Chileno de Antropología. Santiago: Colegio de Antropólogos de Chile, Vol. I (1997a):315-324.

"Economía y uso del espacio en la sociedad aymara actual”, en Actas Segundo Congreso Chileno de Antropología. Santiago: Colegio de Antropólogos de Chile, Vol. 2 (1997b):567-579.

------- Los migrantes aymaras en la ciudad: acceso a educación, vivienda y salud. Documentos de Trabajo. Arica: Corporación Norte Grande, 1996.

GONZÁLEZ, Julián. Vengo de la cordillera al mar. Migrantes aymaras en Iquique. Iquique: Centro de Investigación de la Realidad del Norte, Serie Crónicas, 1988.

------- Los hijos de la desintegración cultural: jóvenes aymaras emigrados. Iquique: Centro de Investigación de la Realidad del Norte, Cuadernos de Investigación Social No 23, 1987.

GONZÁlEZ, Sergio. Chilenizando a Tunupa. La Escuela Pública en el Tarapacá Andino (1880-1990). Santiago: DIBAM, UNAP, CIDBA, 2002.

------- "El arrieraje en Tarapacá durante el ciclo salitrero", en Camanchaca No 8 (1989):10-35.

“Los aymaras de Tarapacá en el ciclo del salitre”, en Camanchaca $\mathrm{N}^{\circ} 5$ (1987):39-44.

GREBE, María Ester. "Migración, identidad y cultura aymará: puntos de vista del actor”, en Chungara No 16-17 (1986a):205-223.

------- "Cambio sociocultural y bilingüismo aymara-español en Isluga”, en Lenguas Modernas $\mathrm{N}^{\circ} 13$ (1986b):37-53.

------- "En torno a los ritos terapéuticos astrales de Isluga”, en Chungara $\mathrm{N}^{\circ}$ 10 (1983):155-164.

GUEVARA, Tomás. Historia de Chile: Chile Prehispano. Santiago: Imprenta Balcells, Vol 2. 1925-1929.

GUNDERMANN, Hans. "Pueblos indígenas en la región atacameña moderna”, en Historia Indígena ํㅜ 10 (2007):63-87.

"Sociedades andinas, municipio y etnicidad; la transformación de los espacios políticos locales andinos en Chile”, en Los Desafíos de la 
Interculturalidad, Identidad, Política y Derecho. Castro, Milka (Ed.). Santiago: Universidad de Chile (2004a):291-328.

"Inicios de siglo en San Pedro de Atacama: procesos, actores e imaginarios en una localidad andina”, en Chungara Revista de Antropología Chilena No 36 (2004b):221-239.

"Las poblaciones indígenas andinas de Chile y la experiencia de la ciudadanía”, en El debate en torno al reconocimiento y los derechos ciudadanos. Mapuches y aymaras. Gundermann, Hans, Rolf Foerster y Jorge Iván Vergara. Santiago: Universidad de Chile y Ril (2003a):19104.

"La formación del espacio andino en Arica y Tarapacá”, en Historia Indígena $\mathrm{N}^{\circ} 7$ (2003b):87-138.

------- "Etnicidad, identidad étnica y ciudadanía en los países andinos y el norte de Chile. Los términos de la discusión y algunas hipótesis de investigación”, en Estudios Atacameños № 13 (1997):9-26.

------- "Comunidad indígena y ciudadanía: La experiencia aymara en el norte de Chile”, en Allpanchis No 46 (1995):91-130.

GUNDERMANN, Hans; GONZÁLEZ, Héctor. Sociedades indígenas y conocimiento antropológico. Aymaras y atacameños de los siglos XIX y $X X$. (2008a, manuscrito).

------- "La antropología andina en Chile y la influencia de las ideas de John Murra” (2008b, manuscrito).

HIDALGO, Jorge. "Tierras, exacciones fiscales y mercado en las sociedades andinas de Arica, Tarapacá y Atacama, 1750-1790”, en La participación Indígena en los Mercados Surandinos. Harris, Olivia, Brooke Larson y Enrique Tandeter (comps.). La Paz: CERES (1987):193-235.

------- Indian society in Arica, Tarapacá and Atacama, 1750-1793, and its response to the rebellion of Tupac Amaru. Londres: University of London. Doctoral Dissertation, 1986.

------- “Complementariedad ecológica y tributo en Atacama: 1683-1792”, en Estudios Atacameños Nº 7 (1984):22-42.

------- “Amarus y cataris: aspectos mesiánicos de la rebelión indígena de 1781 en Cusco, Chayanta, La Paz y Arica”, en Chungara No 10 (1983):117138.

KEARNEY, Michael. Reconceptualizing the Peasantry. Anthropology in Global Perspective. Boulder, Colorado: Westview Press, 1996.

LARRAÍN, Horacio. "Análisis de las causas de despoblamiento entre las comunidades indígenas del Norte Grande, con especial referencia a las hoyas hidrográficas de las Quebradas de Aroma y Tarapacá”, en Norte Grande, Vol. I, Nº 2 (1974):125-154. 
Hans Gundermann K. - Héctor González C.

LATCHAM, Ricardo. Arqueología de la Región Atacameña. Santiago: Prensas de la Universidad de Chile, 1938.

------ La Prehistoria Chilena. Santiago: Imprenta y Litografía Universo, 1928.

------- Los Changos de las Costas de Chile. Santiago: Imprenta Cervantes, 1910.

LEMEIRIS, Jaap. "La lucha por las aguas de los Aymaras del Norte Grande de Chile”, en Cuaderno de Investigación Social. Iquique: Centro de Investigación de la Realidad del Norte, № 20 (1987).

MAMANI, Manuel. "Chacha-warmi. Paradigma e identidad matrimonial aymara en la provincia de Parinacota”, en Chungara Nº 31 (1999):307317.

MAMANI, Juan Carlos. Los Rostros del Aymara en la Provincia de Parinacota, Región de Tarapacá, Chile. Cochabamba: Universidad Mayor de San Simón, Programa de Educación Intercultural Bilingüe para los Países Andinos. Tesis para optar al grado de Magíster en Educación Intercultural Bilingüe, 2003.

MARTÍNEZ, Gabriel. "El sistema de los Uywiris en Isluga”, en VVAA, Homenaje al Dr. Gustavo Le Paige s. j.. Antofagasta: Universidad del Norte (1976):255-327.

------- “Características de orden antropológico y socio-económico de la comunidad de Isluga (I Región)”, en Norte Grande Vol. I, N N 3-4 (1975):403-426.

------- "Humor y sacralidad en el mundo autóctono andino", en Publicación $\mathrm{N}^{\circ}$ 5. Iquique: Universidad de Chile, 1974.

MARTÍNEZ, José Luis. "Los grupos indígenas del Altiplano de Lípez en la Subregión del río Salado”, en Chungara Nº 16-17 (1986):199-201.

-------“'Información sobre el comercio de pescado entre Cobija y Potosí, hecha por el Corregidor de Atacama, don Juan de Segura (19 de julio de 1591)”, en Cuadernos de Historia No 5 (1985):161-171.

MEDINA, José Toribio. Los Aboríjenes de Chile. Santiago: Imprenta Gutenberg, 1882.

MOSTNY, Grete. "Peine, un pueblo atacameño", en Publicación. Santiago: Universidad de Chile, Instituto de Geografía, No 4, 1954.

MUNIZAGA, Carlos. "Un médico herbolario de la actualidad en el norte de Chile”, en Revista Universitaria ํ 26 (1963):243-251.

MUNIZAGA, Carlos; GUNCKEL, Hugo. "Notas etnobotánicas del pueblo atacameño de Socaire”, en Publicaciones del Centro de Estudios Antropológicos. Santiago: Universidad de Chile, N 5, 1958.

MURRA, John. La Organización Económica del Estado Inca. México: Siglo XXI, 1978. 
Formaciones Económicas y Políticas del Mundo Andino. Lima: Instituto de Estudios Peruanos, 1975.

PHILLIPI, Rodulfo. Viage al Desierto de Atacama Hecho de Orden del Gobierno de Chile en el Verano 1853-1854. Halle Sajonia: Librería Eduardo Antón, 1860.

PLATT, Tristán. "Experiencia y experimentación: Los asentamientos andinos en las cabeceras del valle de Azapa”, en Chungara $\mathrm{N}^{\circ} 5$ (1975):33-60.

PROVOSTE, Patricia. Etnia y Comunidad: Los Pueblos del Altiplano de Tarapacá. Antofagasta: Universidad del Norte, Departamento de Sociología, Tesis de Licenciatura en Sociología, 1980.

------- "Diferenciación e integración social en el altiplano chileno", en América Indígena, Vol. XLIX, № 4 (1979):795-811.

------- Antecedentes Socioeconómicos para el Desarrollo del Sector de Isluga. Iquique: Universidad del Norte, Centro Isluga, 1977.

RISOPATRÓN, Luis. La Línea de Frontera con la República de Bolivia. Santiago: Imprenta y Litografía Universo, 1910.

------- La Línea de Frontera en la Puna de Atacama. Santiago: Imprenta Universitaria, 1906.

RODRÍGUEZ, Juan Carlos; MIRANDA, Pablo; MEGE, Pedro. "Etnografía de la Siberia Caliente. Una nota metodológica sobre un estudio en María Elena, el último pueblo salitrero”, en Estudios Atacameños № 22 (2002):105-126.

SAN ROMÁN, Francisco. Desierto i Cordilleras de Atacama. Santiago: Imprenta Nacional, Vol. 3, 1896.

SOLC, Vaclav. “Casa aymara en Enquelga”, en Annals of the Náprstek Museum No 8 (1975):11-146.

TABERNA, Freddy. "El rol de la sociedad andina en el tránsito al socialismo", en Informes de Temas para el Primer Congreso del Hombre Andino. Iquique-Antofagasta: Universidad de Chile (1973):2130.

------- Los Andes y el Altiplano Tarapaqueño. Iquique: Universidad de Chile, Centro de Documentación, 1971.

TUDELA, Patricio. El Estado y la sociedad chilena ante los aymaras de Tarapacá (I Región de Chile): factores y consecuencias de su integración entre 1930 y 1973. Santiago: Comisión Verdad Histórica y Nuevo Trato, Documento de Trabajo No 24, 2002.

UHLE, Max. Fundamentos Étnicos y Arqueología de Arica y Tacna. Quito: Imprenta de la Universidad Central, 1922.

------- Los Aborígenes de Arica y el Hombre Americano. Arica: Imprenta de la Aurora, 1918. 
Hans Gundermann K. - Héctor González C.

VAN KESSEL, Johannes. Holocausto al Progreso. Los Aymaras de Tarapacá. Ámsterdam: CEDLA, Vrije Universiteit, 1980.

WORMALD, Alfredo. Frontera Norte. Santiago: Orbe, 1968.

------- El Mestizo en el Departamento de Arica. Santiago: Universidad del Norte, 1966. 